\title{
Analisis Pengaruh Jenis Pelumas Dasar Sintetik SAE 10W-40 Terhadap Daya, Torsi dan Konsumsi Bahan Bakar Mesin TIPE 2NR
}

\author{
Dikky Antonius ${ }^{1)^{\star}}$, Kimar Turnip ${ }^{1)}$, Priyono Atmadi ${ }^{1)}$, \\ Alexander Gede Lucky Krisnamurti ${ }^{1}$ \\ 1) Jurusan Teknik Mesin Universitas Kristen Indonesia \\ Jalan Maydjen Sutoyo No.2, Cawang, Jakarta Timur, 13650 \\ Email: dicky.antonius@uki.ac.id, kimarturnip@gmail.com, priyono.atmadi@gmail.com, \\ alexanderkrisnamurti@gmail.com
}

doi: https://doi.org/10.24843/METTEK.2019.v05.i01.p02

\begin{abstract}
Abstrak
Kendaraan roda 4/mobil menjadi moda transportasi utama saat ini, dan untuk memelihara kualitas kendaraan, perlu dilakukan perawatan dan servis berkala. Salah satu jenis servis tersebut adalah penggantian pelumas/oli. Saat ini terdapat berbagai merk pelumas yang menawarkan berbagai spesifikasi oli, dimana kualitas oli tersebut dipengaruhi oleh jenis bahan dasarnya. Dalam penelitian ini diadakan pengujian perbandingan pengaruh oli dengan bahan dasar sintetik jenis PAO (Polyalphaolephines), Organic Ester dan PAG (Pholyalkhylenglycol). Pengujian ini dilakukan dengan dynamometer dan software Techstream (Toyota). Hasil menunjukkan bahwa untuk mesin tipe 2NR pelumas dasar jenis PAO mempunyai Daya sekaligus torsi yang paling maksimum (sebesar 98.1 HP pada putaran $6200 \mathrm{RPM}$; dan $126.2 \mathrm{Nm}$ ) dibanding pelumas lainnya. Hal yang sama ditunjukkan dalam hal konsumsi bahan bakar. Pelumas jenis PAO menempati konsumsi bahan bakar paling rendah, sementara PAG menempati posisi yang boros, walaupun ketiga jenis pelumas ini mempunyai tendensi yang sama dalam hal konsumsi bahan bakar untuk kecepatan tinggi.
\end{abstract}

Kata kunci: Kendaraan, Pelumas, Daya, Torsi, Konsumsi Bahan Bakar, Dynamometer, Techstream.

\begin{abstract}
4-Wheeled vehicles/cars become the main mode of transportation recently. To maintain the quality of the vehicles, some maintenance act should be applied periodically. One most favourable is the replacement of lubricants / oil. There are various types of lubricants along with their specifications, where the lubricants quality defined by their components. In this research, three types of synthetic lubricants; PAO (Polyalphaolephines), Organic Ester and PAG (Polyalkylenglycol) are compared. Dynamometer are used as experiment equipment to compare the result of Power along with their Torque, while Techstream software (Toyota) are used to compare their fuel consumption. The result shows that PAO lubricant-type has a highest Power and Torque (98.1 HP pada putaran $6200 \mathrm{RPM}$; dan $126.2 \mathrm{Nm}$ ) compare to the other lubricant-types. The same thing shows in the fuel-consumption experiments. PAO shows the lowest SFC number which means become the most economic lubricant types, while the PAG located to the most extravagant lubricant-type.
\end{abstract}

Keywords: Vehicle, Lubricant, Power, Torque, Fuel Consumption, Dynamometer, Techstream

Penulis korespondensi,

Email: dicky.antonius@uki.ac.id 


\section{PENDAHULUAN}

Pada saat ini kendaraan roda 4/ mobil menjadi salah satu alat transportasi utama dalam kehidupan masyarakat sehari-hari. Oleh karena itu, untuk menjaga kualitas kendaraan, maka perlu dilakukan perawatan (service) secara berkala (periodic) terhadap bagian dalam, ataupun luar mesin. Ada beberapa jenis perawatan yang sering dilakukan, dan sala satu diantaranya adalah penggantian pelumas.

Fungsi utama pelumas sendiri adalah melumasi dan sekaligus mendinginkan setiap bagian-bagian pada mesin untuk mencegah terjadinya benturan antar logam dengan logam komponen mesin seminimal mungkin sehingga tidak terjadi goresan atau keausan. Pemilihan pelumas yang tepat, akan menjaga kualitas dari mesin kendaraan dan mempertahankan ketahanan mesin [1] [2] [3].

Ada dua unsur utama dari bahan baku pelumas, yaitu pelumas dasar dan aditif. Pelumas dasar adalah bahan dasar utama dalam pembuatan pelumas, bahan dasarnya terdiri dari pelumas dasar mineral, sintetis, dan tumbuhan. Sedangkan aditif adalah zat \& senyawa yang ditambahkan ke dalam pelumas dasar dengan fungsi khusus, contohnya adalah despersant dan anti karat. Pelumas yang berkualitas tinggi memiliki keseimbangan yang baik antara pelumas dasar dan aditifnya [4]. Informasi mengenai pengaruh jenis pelumas dasar terhadap performa mesin dari parameter daya, torsi dan konsumsi bahan bakar sangat dibutuhkan sebagai masukan dalam pemilihan pelumas yang sesuai dengan tipe mesin $2 \mathrm{NR}$, informasi ini sangat berguna bagi pemilik kendaraan yang memiliki kendaraan bertipe mesin $2 \mathrm{NR}$ dalam memilih pelumas yang mampu memberikan performa optimal.

Pelumas adalah zat kimia yang bisa berupa cairan atau padatan, digunakan untuk mengurangi gaya gesek pada kedua permukaan yang saling bersentuhan. Pelumas memiliki fungsi utama yaitu sebagai berikut:

1. Melumasi kedua permukaan yang bergesekan untuk mengurangi gaya gesek dan keausan.

2. Membersihkan kotoran dari permukaan logam dan anti karat.

3. Menjadi media penghantar panas keluar

Bahan utama pembuatan pelumas ada dua yaitu pelumas dasar dan zat aditif, umumnya pelumas terdiri dari $90 \%$ pelumas dan $10 \%$ aditif. Menurut jenis pelumas dasarnya pelumas terbagi menjadi :

1. Base Oil Mineral: berasal dari pengolahan minyak bumi.

2. Base Oil Sintetis: berasal dari reaksi kimia (sintesa).

3. Base Oil Tumbuhan: berasal dari ekstraksi tumbuhan.

Dari ketiga jenis base oil, base oil sintesis memiliki keunggulan dibandingkan dengan base oil mineral dan tumbuhan, karena base oil sintetik terdiri dari senyawa yang sangat homogen (sejenis) [4] [5].

Beberapa penelitian telah menggambarkan tentang pengaruh pemilihan bahan dasar terhadap beberapa variable dalam pelumas itu sendiri seperti viskositas, temperature, dan lainnya. Pemilihan bahan dasar sintetik dapat membuat viskositas pelumas bertahan dan mempunyai kestabilan yang terjaga, dan bahkan mempengaruhi konsumsi bahan bakar [6].

Beberapa penelitian juga menunjukkan pengaruh bahan dasar terhadap unjuk kerja dari mesin tertentu, atau pengaruh kerja mesin terhadap kualitas dari pelumas. Unjuk kerja mesin yang terus menerus, akan menurunkan kualitas dari pelumas dan membuatnya menjadi encer. Dengan demikian pelumas akan kurang melekat pada mesin dan membuat mesin mudah bergesekan secara langsung [7] [8] [9].

Namun, dalam beberapa penelitian yang disebutkan, sedikit yang menunjukkan pengaruh langsung pelumas dengan bahan dasar sintetik dengan mesin tipe 2NR Dengan demikian perlu diadakan penelaahan lebih lanjut, agar dapat digunakan sebagai pilihan bagi produsen maupun konsumen dari tipe mesin ini. 


\section{METODE}

\section{Prosedur Penelitian dan Persamaan}

Penelitian dilakukan dengan menggunakan tiga jenis pelumas dasar yaitu PAO (Polyalphaolephins), Organik Ester, dan PAG (Polyalkhyleneglycol). Berikut adalah alur proses penelitian.

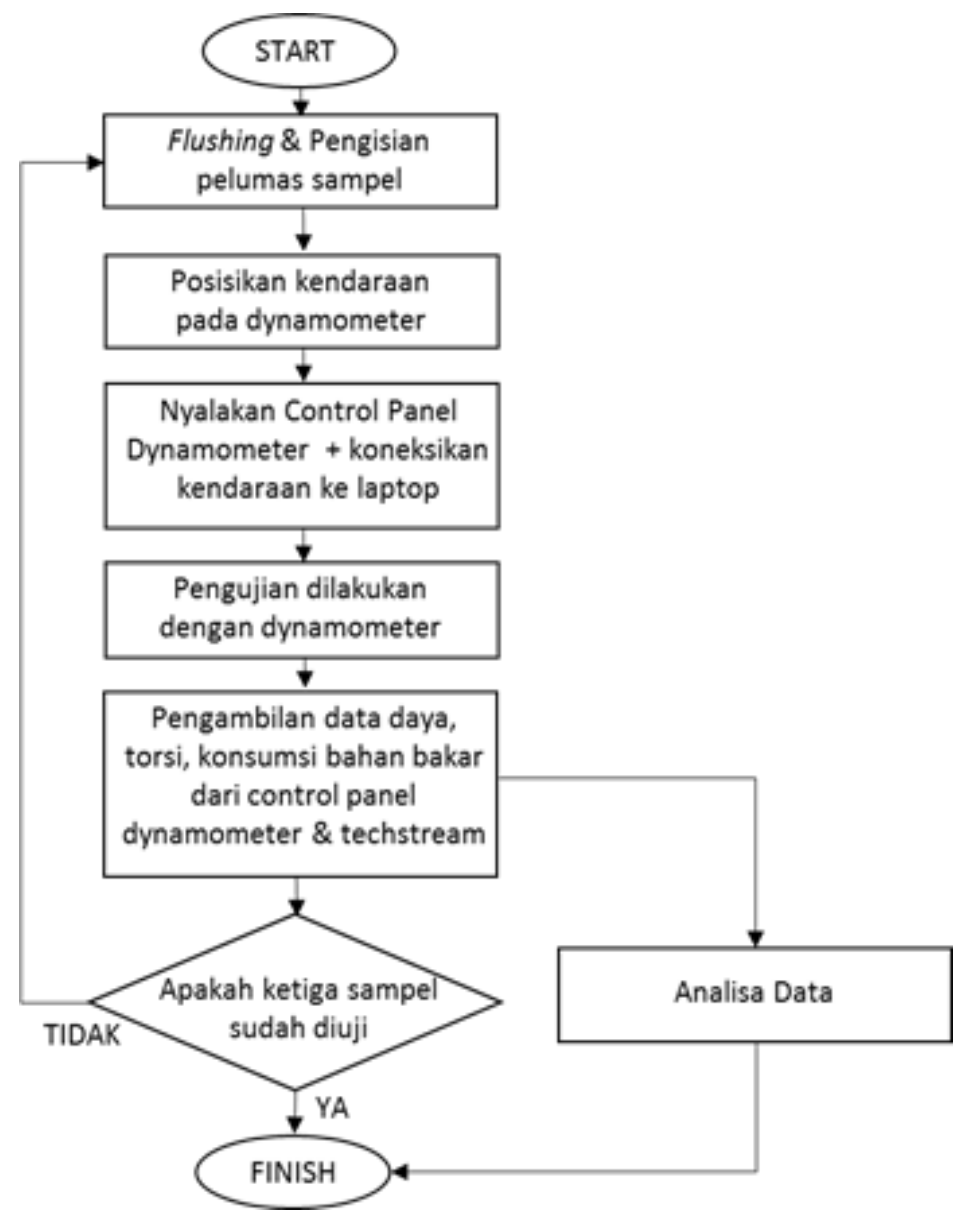

Gambar 1. Alur proses penelitian

1. Percobaan yang dilakukan memiliki 3 sampel pelumas masing-masing sampel berbeda bahan baku base oil nya, dan tidak terkandung bahan aditif di dalamnya.

2. Lakukan proses flushing pelumas di dalam mesin \& ganti filter oli sebelum memasukan sampel pelumas yang akan diuji. Setelah Flushing masukkan pelumas sampel dalam mesin sejumlah 4 liter.

3. Posisikan kendaraan pada alat dynamometer, pasang belt untuk menahan kendaraan supaya kendaraan tidak berubah posisi.

4. Nyalakan control panel dynamometer test untuk data daya + torsi \& koneksikan laptop dengan kendaraan untuk mengambil data konsumsi bahan bakar pada aplikasi techstream

5. Nyalakan kendaraan dan lakukan proses pengujian dengan mengendarai kendaraan dari 0 $6200 \mathrm{rpm}$ dengan perbandingan roda gigi yang mengikuti kenaikan rpm. Setiap kelipatan $1000 \mathrm{rpm}$ harus dikendarai sejauh $1 \mathrm{~km}$ baru dilakukan kenaikan ke $1000 \mathrm{rpm}$ berikutnya.

6. Ambil rekaman data daya \& torsi pada control panel \& data konsumsi bahan bakar pada laptop.

7. Ulangi proses 2 -6 hingga semua sampel pelumas diuji, kemudian lakukan Analisa dari setiap hasil sampel. 
Tabel 1. Spesifikasi dan sifat fisik pelumas dasar sampel

\begin{tabular}{|c|c|c|c|}
\hline Type & Karakteristik & ASTM Test & Nilai Tipikal \\
\hline \multirow{8}{*}{$\begin{array}{l}\text { Polyalphaolephins } \\
\text { (PAO) }\end{array}$} & SAE & & $10 W-40$ \\
\hline & Density at $15^{\circ} \mathrm{C}$ & D 4052 & 0.8468 \\
\hline & $\begin{array}{l}\text { Viscosity Kinematic, } \\
\text { at } 40^{\circ} \mathrm{C}, \mathrm{cSt}\end{array}$ & & \\
\hline & cSt at $100^{\circ} \mathrm{C}$, & D445 & $\begin{array}{l}101.2 \\
11.96\end{array}$ \\
\hline & Viscosity Index & D2270 & 152 \\
\hline & TBN (mgKOH/g) & D2896 & 11.11 \\
\hline & Flash Point, $\mathrm{COC},{ }^{\circ} \mathrm{C}$ & D92 & 248 \\
\hline & Pour Point, ${ }^{\circ} \mathrm{C}$ & D5950 & -21 \\
\hline \multirow{7}{*}{ Organic Ester } & SAE & & $10 W-40$ \\
\hline & Density at $15{ }^{\circ} \mathrm{C}$ & D 4052 & 0.8868 \\
\hline & $\begin{array}{l}\text { Viscosity Kinematic, } \\
\text { at } 40^{\circ} \mathrm{C}, \mathrm{cSt} \\
\text { at } 100^{\circ} \mathrm{C} \text {, } \\
\text { cSt }\end{array}$ & D445 & $\begin{array}{l}115.2 \\
12.01\end{array}$ \\
\hline & Viscosity Index & D2270 & 147 \\
\hline & TBN (mgKOH/g) & D2896 & 11.12 \\
\hline & Flash Point, $\mathrm{COC},{ }^{\circ} \mathrm{C}$ & D92 & 245 \\
\hline & Pour Point, ${ }^{\circ} \mathrm{C}$ & D5950 & -24 \\
\hline \multirow{10}{*}{$\begin{array}{l}\text { Polyalkhyleneglycol } \\
\text { (PAG) }\end{array}$} & SAE & & $10 W-40$ \\
\hline & Density at $15^{\circ} \mathrm{C}$ & D 4052 & 0.8568 \\
\hline & $\begin{array}{l}\text { Viscosity Kinematic, } \\
\text { at } 40^{\circ} \mathrm{C},\end{array}$ & & \\
\hline & & D445 & 117.2 \\
\hline & at $100^{\circ} \mathrm{C}$, & & 12.46 \\
\hline & cSt & & \\
\hline & Viscosity Index & D2270 & 141 \\
\hline & TBN $(\mathrm{mgKOH} / \mathrm{g})$ & D2896 & 11.12 \\
\hline & Flash Point, $\mathrm{COC},{ }^{\circ} \mathrm{C}$ & D92 & 251 \\
\hline & Pour Point, ${ }^{\circ} \mathrm{C}$ & D5950 & -24 \\
\hline
\end{tabular}

Untuk nilai daya dan torsi dapat langsung diambil dari control panel dynamometer, namun untuk nilai konsumsi bahan bakar digunakan metode perhitungan Konsumsi Bahan Bakar Spesifik (SFC) dimana dari aplikasi techstream dapat diambil nilai konsumsi bahan bakar dan waktu konsumsi bahan bakarnya, yang kemudian dapat dimasukkan dalam persamaan (3). 
Dari nilai torsi, daya dan SFC ketiga sampel kemudian dilakukan analisa terhadap sifat fisik pelumasnya, dan menarik hubungan dan pengaruhnya terhadap performa kendaraan, berikut adalah spesifikasi sifat fisik dari ketiga sampel.

Terdapat berbagai parameter dalam mengukur performa mesin / motor bakar, beberapa diantaranya adalah daya, torsi, dan konsumsi bahan bakar

Dynamometer adalah alat pengetesan yang digunakan untuk mengukur performa kendaraan, secara spesifik dynamometer mampu mengukur tenaga, dan torsi kendaraan. Terdapat 2 tipe dynamometer yaitu:

Engine Dynamometer: output mesin langsung dipasang ke alat dyno, dan pengujiannya sebelum mesin dipasang pada body kendaraan.

Chassis Dynamometer: mesin tidak perlu dikeluarkan dari rangka asli, dimana dalam pengetesan harus menggunakan kendaraan asli dan roda mobil memutar roller atau drum mesin dynotest.

Dari hasil dynamometer test kita dapat mendapatkan nilai daya torsi dalam bentuk grafik dan tabel.



Gambar 2. Contoh grafik yang dihasilkan oleh dynamometer, grafik berbentuk linier adalah daya dan grafik berbentuk parabolik adalah torsi

Tech Stream merupakan aplikasi diagnose dari Toyota untuk kendaraan Toyota, Dengan aplikasi ini, pengguna dapat mengetahui kondisi seluruh fungsi yang ada di dalam kendaraan dengan mengkoneksikan kendaraan ke laptop

Dari aplikasi techstream kita dapat mengambil nilai konsumsi bahan bakar yang digunakan dan waktu konsumsinya.

Tabel 2. Contoh tampilan pada techstream yang menampilkan nilai konsumsi bahan bakar dan waktu konsumsinya

\begin{tabular}{lll}
\hline Parameter & Value & Unit \\
\hline Current Fuel Consumption & 0.1 & $\mathrm{Km} / \mathrm{L}$ \\
\hline Average Fuel Consumption & 13.443 & $\mathrm{Km} / \mathrm{L}$ \\
\hline Consumption Fuel Volume & 0.07 & $\mathrm{~L}$ \\
\hline Total Time & $00: 05: 59$ & \\
\hline Distance Traveled & 1,08 & $\mathrm{Km}$ \\
\hline Average Vehicle Speed & 77 & $\mathrm{~km} / \mathrm{h}$ \\
\hline Vehicle Stoppage Rate & 0 & $\%$ \\
\hline
\end{tabular}


1) Daya

Daya adalah besarnya kerja motor persatuan waktu. (Satuan daya yaitu hp (horse power). Daya pada kendaraan roda 4 dapat diukur dengan menggunakan alat dynamometer, sehingga untuk menghitung daya poros dapat diketahui dengan menggunakan persamaan (1).

$$
P=\frac{2 \pi n \mathrm{~T}}{75 \times 60}
$$

$$
\begin{array}{ll}
\mathrm{P} & =\text { daya poros }(\mathrm{hp}) \\
\mathrm{T} & =\text { torsi }(\mathrm{Kgf} . \mathrm{m}) \\
\mathrm{n} & =\text { putaran mesin }(\mathrm{rpm}) \\
1 / 75 & =\text { faktor konversi satuan Kgf.m menjadi hp } \\
1 / 60 & =\text { faktor konversi satuan rpm menjadi kecepatan translasi }(\mathrm{m} / \mathrm{s}) \\
1 \mathrm{hp} & =0,7355 \mathrm{KW} \text { dan } 1 \mathrm{KW}=1,36 \mathrm{~h}
\end{array}
$$

\section{2) Torsi}

Gaya tekan putar pada bagian yang berputar disebut torsi, sepeda motor digerakkan oleh torsi dari crankshaft. Torsi adalah ukuran kemampuan mesin untuk melakukan kerja. Besaran torsi adalah besaran turunan yang biasa digunakan untuk menghitung energi yang dihasilkan dari benda yang berputar pada porosnya. Adapun perumusannya seperti pada persamaan (2).

$$
\begin{aligned}
\mathrm{T} & =\operatorname{lorsi}(\mathrm{N} . \mathrm{m} / \mathrm{Kgf} . \mathrm{m}) \\
\mathrm{F} & =\text { gaya }(\mathrm{N} / \mathrm{Kgf} . \mathrm{m}) \\
\mathrm{R} & =\text { jarak benda ke pusat rotasi (m) }
\end{aligned}
$$

3) Konsumsi Bahan Bakar (Spesific Fuel Consumption)

SFC adalah jumlah bahan bakar per waktunya untuk menghasilkan daya sebesar $1 \mathrm{HP}$. Jadi Konsumsi bahan bakar adalah ukuran ekonomi pemakaian bahan bakar, dengan persamaan (3).

$$
S F C=\frac{\text { Bahan Bakar Digunakan }}{P x t}
$$

$$
\begin{array}{ll}
\text { SFC } & =\text { konsumsi bahan bakar spesifik }(\mathrm{Kg} / \text { sekon.kW) } \\
\text { Bahan bakar digunakan } & =\text { jumlah bahan bakar }(\mathrm{Kg}) \\
\mathrm{P} & =\text { daya }(\mathrm{kW}) \\
\mathrm{t} & =\text { waktu konsumsi bahan bakar (sekon) }
\end{array}
$$

SFC juga bisa dijelaskan sebagai perbandingan antara bahan bakar yang terpakai sebagai input energi dengan daya yang dihasilkan sebagai output. Semakin tinggi nilai SFC artinya semakin banyak energi bahan bakar yang tidak terkonversi menjadi daya. Hal ini disebabkan karena bahan bakar yang masuk dalam silinder tidak terbakar sempurna, ataupun terjadi kerugian termis dan mekanis. 


\section{HASIL DAN PEMBAHASAN}

Dari hasil pengujian dari ketiga jenis pelumas dasar sintetik, berikut adalah hasil dan analisanya.

\section{A. Hasil Pengujian Daya}

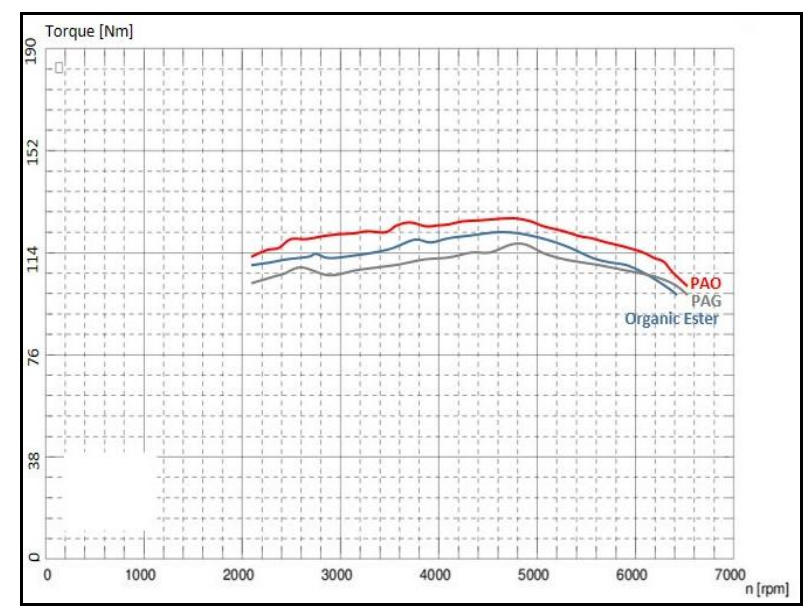

Gambar 3. Grafik daya yang dihasilkan ketiga sampel

Sampel PAO digambarkan dengan garis warna kuning, sampel Organik Ester dengan garis warna ungu, dan sampel PAG dengan garis warna hijau.

Grafik daya yang dihasilkan menghasilkan bentuk linier dimana kenaikan nilai daya berbanding lurus dengan kenaikan RPM, jika dilihat dari persamaan (1), nilai daya berbanding lurus dengan kenaikan RPM, hingga nilai daya mencapai nilai maksimum pada RPM 6200, setelah daya mencapai nilai maksimum, daya akan menurun, hal ini dapat dilihat pada grafik gambar (3).

Tabel 3. Tabel daya dalama kW yang dihasilkan dari ketiga sampel

\begin{tabular}{llllllllll}
\hline \multirow{2}{*}{ Sampel } & \multicolumn{10}{c}{ RPM } \\
\cline { 2 - 11 } & 2100 & 2500 & 3000 & 3500 & 4000 & 4500 & 5000 & 5500 & 6200 \\
\hline PAO & 33,6 & 42,2 & 50,8 & 60,4 & 70,5 & 82,6 & 89,8 & 94,9 & 98,1 \\
\hline Org.Ester & 34,5 & 38,6 & 49,9 & 59,5 & 69.12 & 81,6 & 88,8 & 93,6 & 97,2 \\
\hline PAG & 32,1 & 38,4 & 46 & 55,6 & 65,2 & 75,8 & 86,4 & 90,2 & 97 \\
\hline
\end{tabular}

Dari hasil grafik gambar (3) dan tabel (3), Sampel PAO menghasilkan daya maksimum pada RPM 6200 senilai 98,1 HP, lebih besar 0,9\% dari organic ester dengan daya 97,2 HP dan PAG dengan daya 97,0 HP, hal ini disebabkan karena viskositas kinematik sampel PAO pada suhu kerja $\left(100^{\circ} \mathrm{C}\right)$ yang lebih rendah dibanding sampel lain (kekentalan paling rendah).

Pelumas yang memiliki kekentalan lebih rendah membuat hambatan untuk gerakan mekanik pada motor bakar menjadi lebih rendah dan pergerakan piston menjadi lebih cepat dan leluasa [3].

\section{B. Hasil Pengujian Torsi}

Sampel PAO digambarkan dengan garis warna merah, sampel Organik Ester dengan garis warna biru, dan sampel PAG dengan garis warna abu-abu.ik torsi yang dihasilkan menghasilkan bentuk parabolik dimana jika dilihat pada grafik gambar (4) pada RPM 2000 4700 terjadi kenaikan torsi, namun setelah RPM 4700 terjadi penurunan nilai torsi hingga RPM 6200. Hal ini disebabkan setelah RPM 4700 pembakaran yang terjadi semakin tidak sempurna, sehingga tekanan pada piston semakin berkurang dan nilai torsi pun ikut berkurang, 
adapun rugi-rugi mekanis yang terjadi karena nilai friksi yang juga semakin besar seiring kenaikan RPM

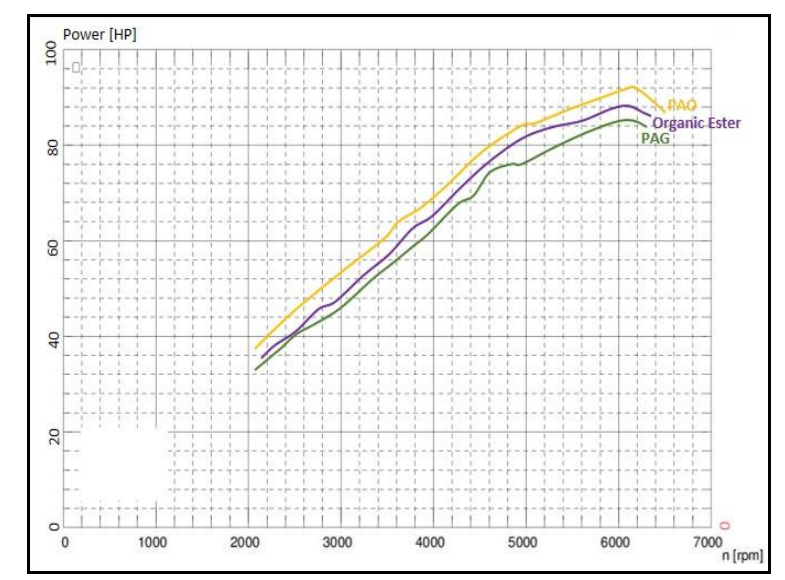

Gambar 4. Grafik torsi yang dihasilkan ketiga sampel

Tabel 4. Tabel torsi dalam satuan Nm yang dihasilkan dari ketiga sampel

\begin{tabular}{llllllllll}
\hline \multirow{2}{*}{ Sampel } & \multicolumn{1}{c}{ RPM } \\
\cline { 2 - 10 } & 2100 & 2500 & 3000 & 3500 & 4000 & 4700 & 5000 & 5500 & 6200 \\
\hline PAO & 112 & 115,2 & 120 & 120 & 123,2 & 126,2 & 124,8 & 120 & 114,4 \\
\hline Org.Ester & 113,6 & 116 & 116 & 118,2 & 120,2 & 124,1 & 122,5 & 115,9 & 111,2 \\
\hline PAG & 104 & 108,8 & 110,4 & 112 & 115,2 & 120,9 & 120 & 115,2 & 113,2 \\
\hline
\end{tabular}

Dari grafik gambar (4) dan tabel (4), Sampel PAO menghasilkan torsi maksimum pada RPM 4700 senilai 126,2 Nm, lebih besar 0,1\% dari Organic Ester dengan torsi 124,1 Nm dan $4 \%$ dari PAG dengan torsi $120,9 \mathrm{Nm}$, hal ini disebabkan karena viskositas kinematik sampel PAO pada suhu kerja yang lebih rendah dibanding sampel lain (kekentalan paling rendah).

Pelumas dengan kekentalan lebih rendah mampu melumasi celah-celah terdalam pada motor bakar dan lebih mampu mengurangi friksi pada ruang bakar dan menghasilkan gaya yang lebih optimal.

\section{Hasil Pengujian Torsi}

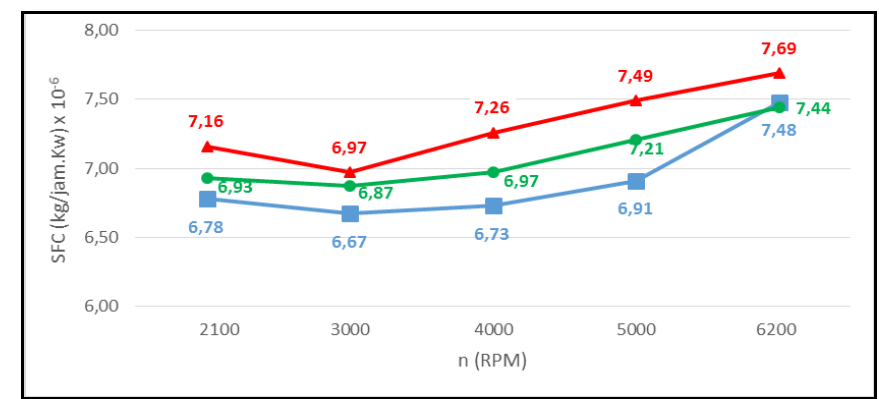

Gambar 5. Grafik SFC yang dihasilkan dari ketiga sampel

Sampel PAO digambarkan dengan garis warna biru, sampel Organik Ester dengan garis warna hijau, dan sampel PAG dengan garis warna merah.

Grafik SFC menghasilkan bentuk linier dimana kenaikan SFC berbanding lurus dengan kenaikan RPM, namun terjadi penurunan nilai SFC pada RPM 3000, hal ini menandakan bahwa pada RPM 3000 rasio berat kendaraan dengan konsumsi bahan bakar tercapai nilai paling optimum. Setelah RPM 3000 nilai SFC mengalami kenaikan berturut-turut hingga 
RPM 6200 yang menunjukan semakin borosnya konsumsi bahan bakar seiring dengan kenaikan RPM, hal ini dapat dilihat dari grafik gambar (5).

Tabel 5. Tabel SFC dalam satuan kg/sec.kW x $10^{4}$ yang dihasilkan dari ketiga sampel

\begin{tabular}{llllll}
\hline \multirow{2}{*}{ Sampel } & \multicolumn{5}{c}{ RPM } \\
\cline { 2 - 6 } & 2100 & 3000 & 4000 & 5000 & 6200 \\
\hline PAO & 6,78 & 6,67 & 6,73 & 6,91 & 7,48 \\
\hline Org.Ester & 6,93 & 6,87 & 6,97 & 7,21 & 7,44 \\
\hline PAG & 7,16 & 6,97 & 7,26 & 7,49 & 7,69 \\
\hline
\end{tabular}

Dari hasil grafik gambar (5) dan tabel (5), Sampel PAO menghasilkan SFC paling rendah dengan rata-rata SFC 6,91 x 10-6 kg/sec.kW, lebih rendah 3\% dari Organik Ester dengan ratarata SFC 7,08 x 10-6 kg/sec.kW dan 4\% dari PAG dengan rata-rata SFC 7,31 x 10-6 $\mathrm{kg} / \mathrm{sec} . \mathrm{kW}$, hal ini disebabkan karena index viskositas dari PAO paling tinggi (kemampuan pelumas mempertahankan kekentalannya pada suhu tinggi).

Pelumas yang mampu mempertahankan kekentalannya pada suhu tinggi dapat menjaga kondisi mesin tetap optimum, sehingga konsumsi bahan bakar yang digunakan akan lebih rendah..

\section{SIMPULAN}

Dari ketiga bahan dasar base oil, base oil PAO (Polyalphaolephins) dapat memberikan unjuk kerja yang lebih baik dibanding base oil Organic Ester dan PAG (Polyalkhyleneglycol) dengan daya maksimum sebesar 98,1 HP, torsi maksimum sebesar 126,2 Nm dan rata-rata nilai SFC sebesar 6,91 x 10-6 kg/sec.kW. Oleh Karen itu, untuk mesin bensin tipe 2NR berkapasitas $1500 \mathrm{cc}$, paling direkomendasikan menggunakan pelumas dengan bahan dasar base oil PAO (Polyalphaolephins). Karena pelumas dengan base oil tersebut mampu memberikan unjuk kerja maksimal pada mesin bensin tipe $2 \mathrm{NR}$.

\section{UCAPAN TERIMA KASIH}

Ucapan terima kasih sebesar-besarnya saya berikan kepada Bapak Ir. Kimar Turnip, M.Si. dan Bapak Ir. Priyono Atmadi, DEA. Yang telah membimbing dalam penulisan jurnal ilmiah ini, serta direksi dan rekan - rekan karyawan PT. Toyota-Astra Motor yang telah banyak membantu dalam usaha memperoleh data guna menyelesaikan jurnal ilmiah ini..

\section{DAFTAR PUSTAKA}

[1] Sukirno, Pelumasan dan Teknologi Pelumas, Jakarta: Departemen Teknik Kimia Fakultas Teknik Universitas Indonesia, 1988.

[2] Suyanto, Teori Motor Bensin, Jakarta: Departemen Pendidikan Nasional, 1989.

[3] Yubaidah, Monitoring Kualitas Mesin Otomotif, Surabaya: Universitas Kristen Petra, 2008.

[4] Pertamina, "Materi Level 1 Lubricants," Jakarta, 2012.

[5] M. B. A. L. S. T. Teknologi, Bahan Ajar Motor Bakar, Jakarta, 2017.

[6] D. T. M.arisandi, "ANALISA PENGARUH BAHAN DASAR PELUMAS TERHADAP VISKOSITAS PELUMAS DAN KONSUMSI BAHAN BAKAR," Momentum, vol. 8, no. ft-UNWAHAS, pp. 56-61, 2012.

[7] A. P. Wayan Diatniti, "Analisis Penurunan Kualitas Minyak Pelumas Pada Kendaraan Bermotor Berdasarkan Nilai Viskositas, Warna dan Banyaknya Bahan Pengotor," JURNAL Teori dan Aplikasi Fisika, vol. 3, pp. 171 - 178, 2015. 
[8] I. Murdianto, PERBEDAAN PERFORMA (DAYA, TORSI ,KONSUMSI BAHAN BAKAR) MENGGUNAKAN INJEKTOR STANDART DAN INJEKTOR RACING DENGAN BAHAN BAKAR PERTAMAX DAN PERTAMAX PLUS PADA SEPEDA MOTOR V-XION, Semarang: Universitas Negeri Semarang, 2016.

[9] R. A. M. Syafwansyah Effendi, "PENURUNAN NILAI KEKENTALAN AKIBAT PENGARUH KENAIKAN TEMPERATUR PADA BEBERAPA MEREK MINYAK PELUMAS," Jurnal INTEKNA, vol. 14, pp. 1 - 9, 2014. 